\title{
Mechanisms of Diagonal-Shear Failure in Reinforced Concrete Beams analyzed by AE-SiGMA*
}

\author{
Kentaro OHNO ${ }^{* *}$, Shinichiro SHIMOZONO***, Yosuke SAWADA ${ }^{* *}$ \\ and Masayasu OHTSU** \\ ${ }^{* *}$ Graduate School of Science and Technology, Kumamoto University, \\ 2-39-1, Kurokami, Kumamoto 860-8555, Japan \\ E-mail: ohtsu@gpo.kumamoto-u.ac.jp
}

\begin{abstract}
Serious shear failures in reinforced concrete (RC) structures were reported in the Hanshin-Awaji Earthquake. In particular, it was demonstrated that a diagonal-shear failure could lead to disastrous damage. However, mechanisms of the diagonal-shear failure in RC beams have not been completely clarified yet. In this study, the diagonal-shear failure in RC beams is investigated, applying acoustic emission (AE) method. To identify source mechanisms of AE signals, SiGMA (Simplified Green's functions for Moment tensor Analysis) procedure was applied. Prior to four-point bending tests of RC beams, theoretical waveforms were calculated to determine the optimal arrangement of AE sensors. Then, cracking mechanisms in experiments were investigated by applying the SiGMA procedure to $\mathrm{AE}$ waveforms. From results of the SiGMA analysis, dominant motions of micro-cracks are found to be of shear crack in all the loading stages. As the load increased, the number of tensile cracks increased and eventually the diagonal-shear failure occurred in the shear span. Prior to final failure, AE cluster of micro-cracks was intensely observed in the shear span. To classify AE sources into tensile and shear cracks, AE parameter analysis was also applied. As a result, most of AE hits are classified into tensile cracks. The difference between results obtained by the AE parameter analysis and by the SiGMA analysis is investigated and discussed.
\end{abstract}

Key words: Acoustic Emission, Diagonal-Shear Failure, Parameter Analysis, Reinforced Concrete Beam, SiGMA Analysis

\section{Introduction}

Recently, the deterioration of aged concrete structures, which were built in the period of high economic growth, has become a serious problem in Japan. In addition, reinforced concrete (RC) structures were disastrously damaged in the Hanshin-Awaji Earthquake ${ }^{(1)}$. It is well known in concrete engineering that typical failure patterns in RC beams are observed as bending failure, shear failure and bond-splitting failure. Among them, the shear failure occurs in such a brittle nature as to be protected in design. However, the mechanisms of the diagonal-shear failure in RC beams have not been completely clarified yet. So far, it is found that the occurrence of the diagonal-shear failure in the RC beam depends on the ratio of the shear span to the effective depth (a/d) (shown Fig. 1).

Prior to maintenance and repair of a concrete structure, a diagnostic inspection on the current state of the deterioration is necessary. To this end, acoustic emission (AE) method 
has been applied to detect micro-cracks in concrete structures ${ }^{(2)}$. For a quantitative inverse analysis of AE waveforms, SiGMA (Simplified Green's functions for Moment tensor Analysis) procedure has been developed ${ }^{(3)}$. Kinematics of AE source, such as crack location, crack type and crack orientation, can be analyzed from recorded AE waveforms.

In the present paper, the SiGMA analysis is applied to four-point bending tests of RC beams. First, theoretical waveforms are calculated to determine a proper array of AE sensors. Theoretical waveforms are synthesized by applying the dislocation models and Green's functions in a half space. Then AE waveforms are detected during the process of the diagonal-shear failure of an RC beam and are analyzed by the SiGMA procedure. Since classification of cracks is proposed by using AE parameters ${ }^{(4)}$, results of the AE parameter analysis are compared with those of the SiGMA analysis, and the difference is discussed.

\section{SiGMA Analysis}

\subsection{Moment Tensor and Crack Model}

According to the generalized theory of $\mathrm{AE}^{(5)}, \mathrm{AE}$ waves (elastic waves) are generated by dynamic-crack (dislocation) motions inside a solid. AE waveform $u_{i}(x, t)$ due to displacement discontinuity $b(y, t)$ is represented by moment tensor $m_{p q}$,

$$
u_{i}(x, t)=G_{i p, q}\left(x, x^{\prime}, t\right) m_{p q} * S(t)
$$

where $G_{i p, q}$ is the spatial derivative of Green's functions, $S(t)$ represents source kinetics (source time function) and $*$ denotes the convolution integral. An applicability of Eq. 1 to $\mathrm{AE}$ wave motions has been already confirmed by a simulation analysis ${ }^{(6)}$.

Mathematically, the moment tensor in Eq. 1 is defined by the tensor product of the elastic constants, the normal vector $\boldsymbol{n}$ to the crack surface and the crack-motion (dislocation or Burgers) vector $\boldsymbol{l}$.

$$
m_{p q}=C_{p q i j} l_{i} n_{j} \Delta V
$$

Here $C_{p q i j}$ is the tensor of elastic constants and $\Delta V$ is the crack volume. In an isotropic material, the moment tensor $m_{p q}$ is derived from Eq. 2,

$$
m_{p q}=\left(\lambda l_{k} n_{k} \delta_{p q}+\mu l_{p} n_{q}+\mu l_{q} n_{p}\right) \Delta V
$$

where $\lambda$ and $\mu$ are Lame constants.

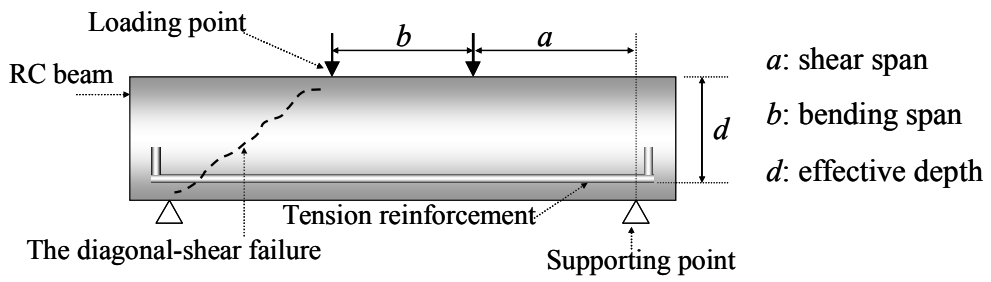

Fig. 1 The model of RC beam

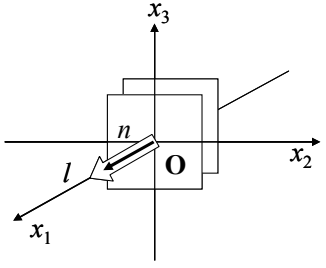

(a) Tensile dislocation model

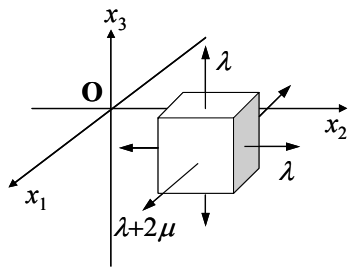

(b) Moment tensor elements

Fig. 2 The model of a tensile crack 


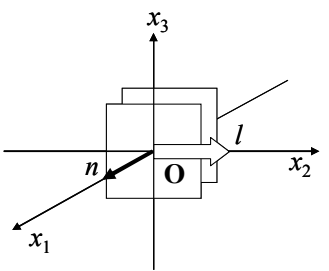

(a) Shear dislocation model

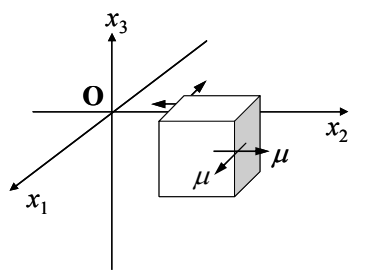

(b) Moment tensor elements

Fig. 3 The model of a shear crack

In the case that a tensile crack occurs on a crack surface parallel to the $x_{2}-x_{3}$ plane and opens in the $x_{1}$ direction as shown in Fig. 2, the crack vector $\boldsymbol{l}=(1,0,0)$ and the normal vector $\boldsymbol{n}=(1,0,0)$. The corresponding moment tensor is represented in Fig. 2(b). Substituting these into Eq. 3, the moment tensor becomes,

$$
m_{p q}=\left[\begin{array}{ccc}
\lambda+2 \mu & 0 & 0 \\
0 & \lambda & 0 \\
0 & 0 & \lambda
\end{array}\right] \Delta V .
$$

The other case is a shear crack parallel to the $x_{2}-x_{3}$ plane as shown in Fig. 3 . The crack vector $\boldsymbol{l}=(0,1,0)$, and the normal vector $\boldsymbol{n}=(1,0,0)$. The moment tensor is represented,

$$
m_{p q}=\left[\begin{array}{ccc}
0 & \mu & 0 \\
\mu & 0 & 0 \\
0 & 0 & 0
\end{array}\right] \Delta V .
$$

\subsection{SiGMA procedure}

To determine the components of the moment tensor from detected AE waveforms, Eq. 1 is simplified, taking into account only the first motion $A(x)$ of P-wave in the far field,

$$
A(x)=C_{S} \cdot \frac{\operatorname{Ref}(\boldsymbol{t}, \boldsymbol{\gamma})}{R} \cdot \gamma_{p} m_{p q} \gamma_{q} D A
$$

where $C_{S}$ is the calibration coefficient of the sensor sensitivity and material constants, the reflection coefficient $\operatorname{Ref}(\boldsymbol{t}, \gamma)$ is obtained as $\boldsymbol{t}$ is the direction of sensor sensitivity, $D A$ is area of crack surface and $\gamma$ is the direction vector of distance $R$ from the source to the observation point $x$.

Since the moment tensor is symmetric and of the second order, the number of independent unknowns $m_{p q}$ is six. A multi-channel observation of the first motions at more than six sensor locations can provide sufficient information to solve Eq. 6 .

In the location procedure, the source (crack) location $\boldsymbol{x}^{\prime}$ in Eq. 1 is determined from the arrival time differences $t_{i}$ between the observation point $\boldsymbol{x}_{\boldsymbol{i}}$ and $\boldsymbol{x}_{\boldsymbol{i}+\mathbf{1}}$, by solving equations,

$$
R_{i}-R_{i+1}=\left|x_{i}-x^{\prime}\right|-\left|x_{i+1}-x^{\prime}\right|=v_{p} t_{i} .
$$

Here $v_{p}$ is the velocity of $\mathrm{P}$-wave.

After solving Eq. 7, the reflection coefficient $\operatorname{Ref}(t, \gamma)$, the distance $R$, and direction vector $\gamma$ are readily obtained to solve Eq. 6. The amplitude of the first motions at more than six channels are substituted into Eq. 6, and all the elements of the moment tensor are determined.

\subsection{Eigenvalue Analysis of the Moment Tensor}

To identify source kinematics, a unified decomposition of eigenvalues of the moment tensor has been proposed ${ }^{(3)}$. In general, crack motion on the crack surface consists of slip motion (shear components) and crack-opening motion (tensile components), as illustrated in Fig. $4^{(7)}$. Thus, it is assumed that the eigenvalues of the moment tensor consist of those of a shear crack and a tensile crack, as the both principle axes are identical. Then, the eigenvalues are decomposed uniquely into those of a shear crack, the deviatoric components 
shear components
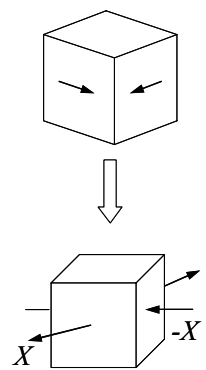

eigenvalues of shear

tensile components

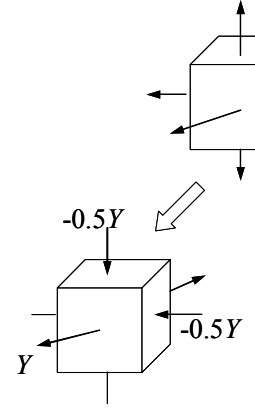

deviatoric of tensile

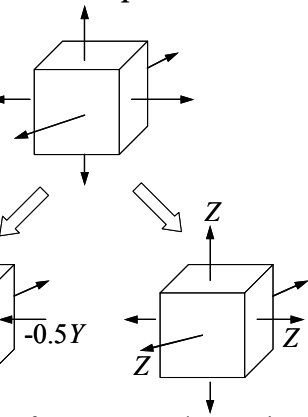

Hydrostatic mean of tensile

Fig. 4 Unified decomposition of eigenvalues of the moment tensor

Table 1. Mixture proportion and properties of concrete.

\begin{tabular}{|c|c|c|c|c|c|c|c|c|}
\hline \multirow{2}{*}{$\begin{array}{c}\text { Maximum } \\
\text { aggregate size } \\
\left(\mathrm{G}_{\max }\right) \\
(\mathrm{mm})\end{array}$} & \multirow{2}{*}{$\begin{array}{c}\text { Water to } \\
\text { cement ratio } \\
\text { W/C } \\
(\%)\end{array}$} & \multicolumn{4}{|c|}{ Weight per $1 \mathrm{~m}^{3}$ concrete } & \multirow[b]{2}{*}{$\begin{array}{l}\text { Admixture } \\
\text { (cc) }\end{array}$} & \multirow[b]{2}{*}{$\begin{array}{c}\text { Slump } \\
(\mathrm{cm})\end{array}$} & \multirow[b]{2}{*}{$\begin{array}{l}\text { Air } \\
(\%)\end{array}$} \\
\hline & & $\begin{array}{c}\text { Water } \\
(\mathrm{kg})\end{array}$ & $\begin{array}{c}\text { Cement } \\
(\mathrm{kg})\end{array}$ & $\begin{array}{c}\text { Fine } \\
\text { aggregate } \\
(\mathrm{kg})\end{array}$ & $\begin{array}{c}\text { Coarse } \\
\text { aggregate } \\
(\mathrm{kg})\end{array}$ & & & \\
\hline 20 & 55 & 175 & 318 & 717 & 1178 & 732 & 8 & 6.0 \\
\hline
\end{tabular}

Table 2. Mechanical properties of hardened concrete.

\begin{tabular}{|c|c|c|c|}
\hline $\begin{array}{c}\text { Compressive } \\
\text { strength } \\
(\mathrm{MPa})\end{array}$ & $\begin{array}{c}\text { Tensile } \\
\text { strength } \\
(\mathrm{MPa})\end{array}$ & $\begin{array}{c}\text { Poisson's } \\
\text { Ratio }\end{array}$ & $\begin{array}{c}\text { P-wave } \\
\text { Velocity } \\
(\mathrm{m} / \mathrm{sec})\end{array}$ \\
\hline 29.7 & 3.03 & 0.2 & 4230 \\
\hline
\end{tabular}

of a tensile crack and the isotropic (hydrostatic mean) components of a tensile crack. Eventually the decomposition leads to relations,

$$
1.0=X+Y+Z
$$

the intermediate eigenvalue / the maximum eigenvalue $=0-Y / 2+Z$

the minimum eigenvalue / the maximum eigenvalue $=-X-Y / 2+Z$

The pure shear crack corresponds to the case $X=1$ and $Y=Z=0$, while the pure tensile crack is identical to the case $X=0$. In the present SiGMA code, AE sources with shear ratios less than $40 \%$ are classified as tensile cracks. When the ratio $X$ is larger than $60 \%$, the $\mathrm{AE}$ source is classified as a shear crack. In between $40 \%$ and $60 \%$, the crack are referred to as mixed-mode.

After determining the crack type, the direction of crack motion is derived from the eigenvectors. From the eigenvalue analysis, three eigenvectors $\boldsymbol{e}_{1}, \boldsymbol{e}_{2}, \boldsymbol{e}_{3}$ are also obtained. Theoretically, these are derived as,

$$
\begin{aligned}
& e_{1}=\boldsymbol{l}+\boldsymbol{n} \\
& \boldsymbol{e}_{2}=\boldsymbol{l} \times \boldsymbol{n} \\
& \boldsymbol{e}_{3}=\boldsymbol{l}-\boldsymbol{n}
\end{aligned}
$$

Here $\times$ denotes the vector product, and the vectors $\boldsymbol{l}$ and $\boldsymbol{n}$ are interchangeable. In the case of a tensile crack, the vector $\boldsymbol{l}$ is parallel to the vector $\boldsymbol{n}$. Thus, the vector $\boldsymbol{e}_{1}$ could give the direction of crack-opening, while the sum $\boldsymbol{e}_{1}+\boldsymbol{e}_{3}$ and the difference $\boldsymbol{e}_{1}-\boldsymbol{e}_{3}$ give the two vectors $\boldsymbol{l}$ and $\boldsymbol{n}$ for a shear crack.

\section{Theoretical AE Waveforms}

\subsection{Specimen and Test Set-Up}

Mixture proportion of concrete is given in Table 1. Mechanical properties of hardened concrete are summarized in Table 2. In the case where the ratio of the shear span to the 


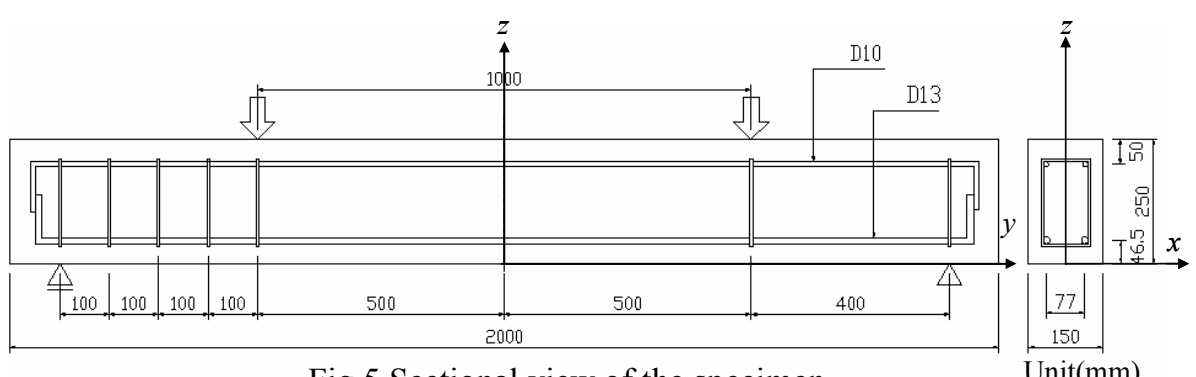

Fig.5 Sectional view of the specimen

Table 3. The coordinate of the assumed crack.

\begin{tabular}{|c|c|c|c|}
\hline & $x(\mathrm{~m})$ & $y(\mathrm{~m})$ & $z(\mathrm{~m})$ \\
\hline No.1 & 0.020 & 0.800 & 0.080 \\
\hline No.2 & 0.040 & 0.600 & 0.200 \\
\hline No.3 & -0.030 & 0.700 & 0.175 \\
\hline No.4 & -0.050 & 0.900 & 0.030 \\
\hline No.5 & 0.055 & 0.500 & 0.230 \\
\hline
\end{tabular}

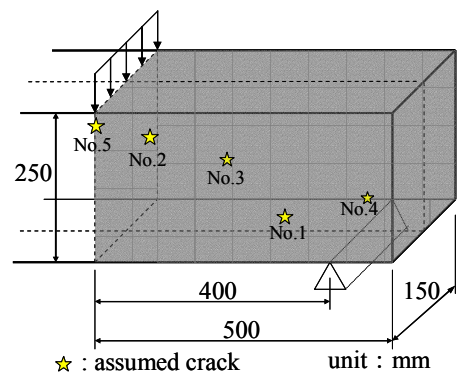

Fig. 6 Assumed crack locations

effective depth, a/d, is smaller than 2.7 , it is known that the diagonal-shear failure occurs in the $\mathrm{RC}$ beam. In an experiment, the ratio $\mathrm{a} / \mathrm{d}$ was set to 1.97 . In order to confirm generation of the diagonal-shear failure, $\mathrm{RC}$ beams of dimensions $150 \mathrm{~mm} \times 250 \mathrm{~mm} \times$ $2000 \mathrm{~mm}$ with $400 \mathrm{~mm}$ shear span were designed. Configuration of the specimen is illustrated in Fig. 5. Generally, in order to increase shear capacity of RC beam, stir-rups are arranged in the shear span. No stir-rup reinforcement was arranged in the right-hand shear span as shown in Fig. 5, as the diagonal-shear failure could be localized. Because AE wave amplitude decreases immediately in the concrete, it is necessary that whole target area is covered with $\mathrm{AE}$ sensors in the SiGMA analysis. In Fig. 5, D10 means a reinforcing-steel bar of $10 \mathrm{~mm}$ diameter and D13 denotes that of $13 \mathrm{~mm}$ diameter. The yield stress of these bars are both $295 \mathrm{~N} / \mathrm{mm}^{2}$.

\subsection{Crack Models}

In order to determine the optimal array of AE sensors, theoretical waves were synthesized. Elastic waves propagated from a source were assumed to be detected as AE signals at the sensor locations. Based on the source location and moment tensors, elastic waves were calculated theoretically at the sensor locations ${ }^{(5),(8),(9),(10)}$.

The origin of $x-y$ coordinates is set at the center of specimen and the origin of $z$ coordinate is at the bottom of the specimen. Cracks of five tensile cracks, five in-plane-shear cracks and five out-of-plane-shear cracks were modeled in the right side shear span of the specimen in Fig. 5. Locations of these cracks are given in Table 3 and Fig. 6.

Tensile cracks, of which the normal vector $\boldsymbol{n}=(0,1 / \sqrt{2}, 1 / \sqrt{2})$ and the crack vector $\boldsymbol{l}=(0$, $1 / \sqrt{ } 2,1 / \sqrt{ } 2$ ), occurs as inclined $45^{\circ}$ to $y$-axis. The moment tensor of a tensile crack is represented as,

$$
m_{p q}=\left[\begin{array}{ccc}
\lambda & 0 & 0 \\
0 & \lambda+\mu & \mu \\
0 & \mu & \lambda+\mu
\end{array}\right] \Delta V
$$

The moment tensor of in-plane-shear cracks of the case $\boldsymbol{l}=(0,1 / \sqrt{2},-1 / \sqrt{2})$ is represented as, 
Table 4. The coordinate of AE sensor location.

\begin{tabular}{|c|c|c|c|}
\hline & $x(\mathrm{~m})$ & $y(\mathrm{~m})$ & $z(\mathrm{~m})$ \\
\hline \multicolumn{4}{|c|}{ TYPE 1} \\
\hline $1 \mathrm{CH}$ & 0.030 & 0.700 & 0.000 \\
\hline $2 \mathrm{CH}$ & 0.075 & 0.600 & 0.120 \\
\hline $3 \mathrm{CH}$ & 0.000 & 0.800 & 0.250 \\
\hline $4 \mathrm{CH}$ & -0.075 & 0.750 & 0.200 \\
\hline $5 \mathrm{CH}$ & -0.075 & 0.650 & 0.050 \\
\hline $6 \mathrm{CH}$ & -0.025 & 1.000 & 0.125 \\
\hline \multicolumn{4}{|c|}{ TYPE 2} \\
\hline $1 \mathrm{CH}$ & 0.030 & 0.700 & 0.000 \\
\hline $2 \mathrm{CH}$ & 0.075 & 0.600 & 0.120 \\
\hline $3 \mathrm{CH}$ & 0.000 & 0.800 & 0.250 \\
\hline $4 \mathrm{CH}$ & -0.075 & 0.750 & 0.200 \\
\hline $5 \mathrm{CH}$ & -0.075 & 0.650 & 0.050 \\
\hline $6 \mathrm{CH}$ & 0.075 & 0.900 & 0.105 \\
\hline
\end{tabular}

Table 5. Results of SiGMA analysis $(6 \mathrm{CH})$

\begin{tabular}{|c|c|c|c|}
\hline TYPE 1 & \multicolumn{3}{|c|}{ Results of SiGMA analysis } \\
\hline Assumed crack & Tensile-mode & Mixed-mode & Shear-mode \\
\hline Tensile & 3 & 0 & 2 \\
\hline In-plane-shear & 3 & 0 & 2 \\
\hline Out-of-plane-shear & 2 & 1 & 2 \\
\hline \multicolumn{5}{|l}{} \\
\hline TYPE 2 & Tensile-mode & Mixed-mode & Shear-mode \\
\hline Tensile & 3 & 1 & 1 \\
\hline In-plane-shear & 1 & 2 & 2 \\
\hline Out-of-plane-shear & 1 & 1 & 3 \\
\hline
\end{tabular}

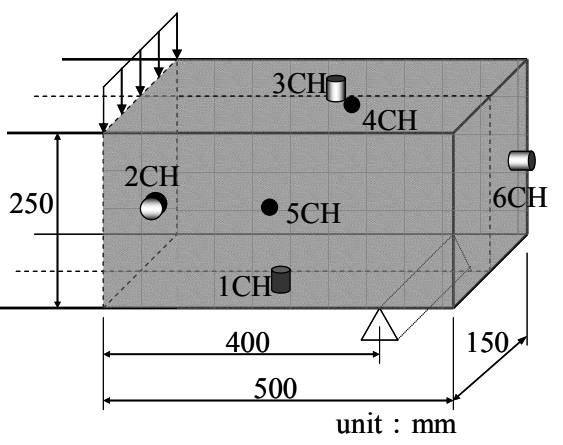

Fig. 7 Type 1 AE sensor location.

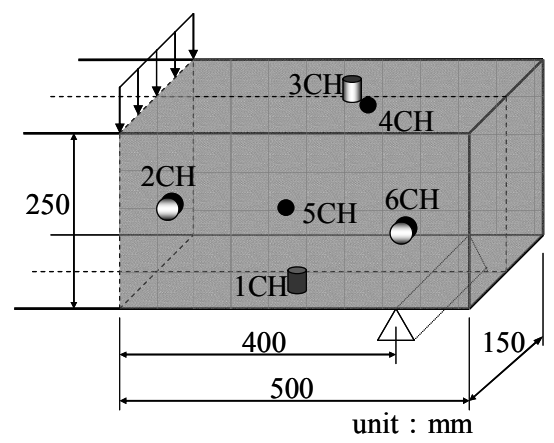

Fig. 8 Type 2 AE sensor location.

$$
m_{p q}=\left[\begin{array}{ccc}
0 & 0 & 0 \\
0 & \mu & 0 \\
0 & 0 & -\mu
\end{array}\right] \Delta V
$$

The moment tensor of out-of-plane-shear cracks is obtained as setting $\boldsymbol{l}=(-1,0,0)$,

$$
m_{p q}=\left[\begin{array}{ccc}
0 & -\frac{1}{\sqrt{2}} \mu & -\frac{1}{\sqrt{2}} \mu \\
-\frac{1}{\sqrt{2}} \mu & 0 & 0 \\
-\frac{1}{\sqrt{2}} \mu & 0 & 0
\end{array}\right] \Delta V
$$

Setting an array of six sensors as one group, two types of arrays were arranged in the shear span of the specimen. The coordinates of sensor locations are given in Table 4, Figs. 7 and 8 . Three types of tensile, mixed-mode and shear cracks were modeled at the shear span. Theoretical AE waves generated due to these cracks are calculated at two types of sensor arrays. Then the SiGMA analysis was carried out. Results are summarized, as follows.

In both arrays, location errors between the modeled cracks and results of the SiGMA analysis are negligible on locations of No.1, No.2, No.3 and No.4 cracks in Table 3. Only location error of $1 \mathrm{~mm}$ was found in No.5 crack. Results of classified crack modes are given in Table 5. It is found that the accuracy of crack classification is not good enough for both sensor arrays.

To improve the accuracy of crack classification, eight AE sensors were arranged in the shear span of the specimen. The coordinates of sensor array and results of the SiGMA analysis are given in Tables 6,7 and Fig. 9. For this case, location errors between the 
Table 6. The coordinate of $\mathrm{AE}$ sensor location. $(8 \mathrm{CH})$

\begin{tabular}{|c|c|c|c|}
\hline & $x(\mathrm{~m})$ & $y(\mathrm{~m})$ & $z(\mathrm{~m})$ \\
\hline $1 \mathrm{CH}$ & 0.030 & 0.700 & 0.000 \\
\hline $2 \mathrm{CH}$ & 0.075 & 0.600 & 0.120 \\
\hline $3 \mathrm{CH}$ & 0.000 & 0.800 & 0.250 \\
\hline $4 \mathrm{CH}$ & -0.075 & 0.750 & 0.200 \\
\hline $5 \mathrm{CH}$ & -0.075 & 0.650 & 0.050 \\
\hline $6 \mathrm{CH}$ & -0.025 & 1.000 & 0.125 \\
\hline $7 \mathrm{CH}$ & 0.075 & 0.900 & 0.105 \\
\hline $8 \mathrm{CH}$ & 0.030 & 1.000 & 0.050 \\
\hline
\end{tabular}

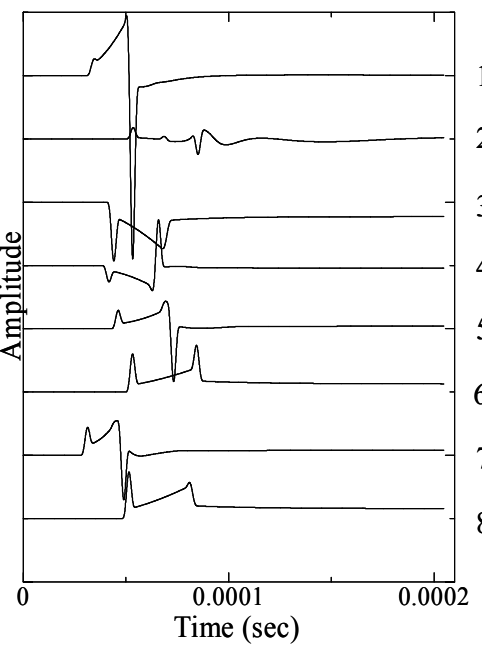

(a) No.1 crack

Table 7. Results of SiGMA analysis $(8 \mathrm{CH})$

\begin{tabular}{|c|c|c|c|}
\hline $8 \mathrm{CH}$ & \multicolumn{3}{|c|}{ Results of SiGMA analysis } \\
\hline Assumed crack & Tensile-mode & Mixed-mode & Shear-mode \\
\hline Tensile & 5 & 0 & 0 \\
\hline In-plane-shear & 0 & 1 & 4 \\
\hline Out-of-plane-shear & 0 & 0 & 5 \\
\hline
\end{tabular}

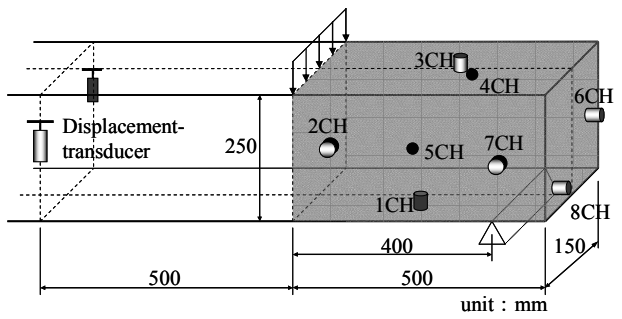

Fig. 9 AE sensor location $(8 \mathrm{CH})$.

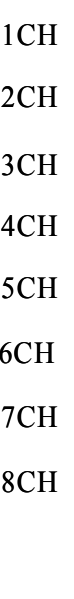

$2 \mathrm{CH}$

$3 \mathrm{CH}$

$4 \mathrm{CH}$

(6)

$8 \mathrm{CH}$

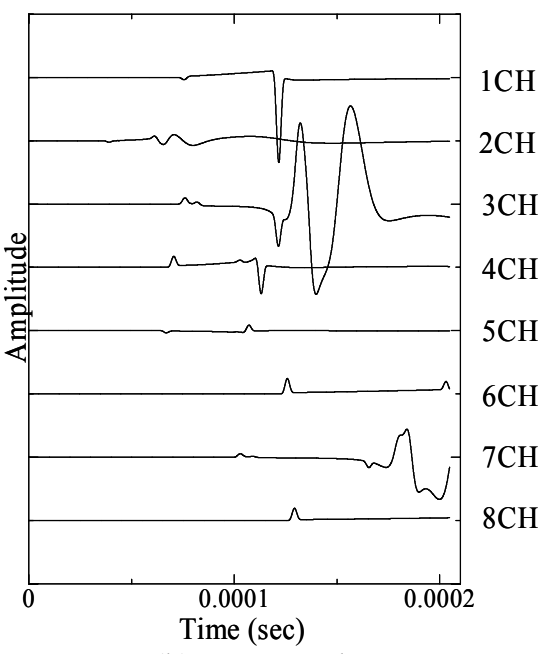

(b) No.5 crack

Fig. 10 The theoretical waveforms due to in-plane-shear cracks

assumed cracks and results of the SiGMA analysis were identical to those of 6-channel sensor arrays. In the case of tensile cracks and out-of-plane-shear cracks, crack modes are precisely classified by the SiGMA analysis. One of in-plane-shear cracks is classified as mixed-mode. From these results, 8-channel sensor array was selected in experiments. Figure 10 shows theoretical waveforms due to in-plane-shear cracks at No. 1 crack and No. 5 crack. It is found that the first amplitudes of No. 5 waveforms are smaller than those of waveforms of No.1. This is because this crack location is far from the sensor array. It suggests that the moment tensor obtained for No.1 crack might be not accurate enough.

\section{AE Monitoring of RC Beam}

\subsection{Experimental Procedure}

A four-point bending test was carried out, recording $\mathrm{AE}$ waves in a laboratory. $\mathrm{AE}$ signals were detected by AE sensors of $150 \mathrm{kHz}$ resonance (R15, PAC) and recorded at 1 $\mathrm{MHz}$ sampling frequency (DiSP, PAC). AE hits were amplified with $40 \mathrm{~dB}$ gain in a pre-amplifier and $20 \mathrm{~dB}$ gain in a main amplifier.

Based on results of the simulation analysis, 8 AE sensors were arranged. All AE sensors covered the whole area of the shear span without stir-rups as shown in Fig. 9. During the test, displacements on two sides were measured with displacement-transducers. 


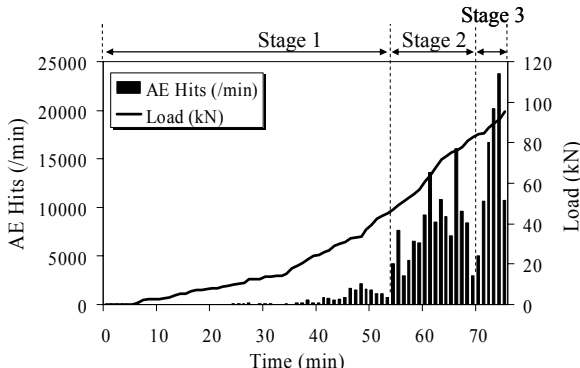

Fig. 11 AE generation behavior in the bending test.

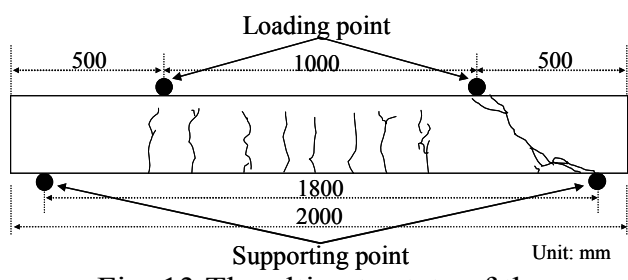

Fig. 13 The ultimate state of the specimen

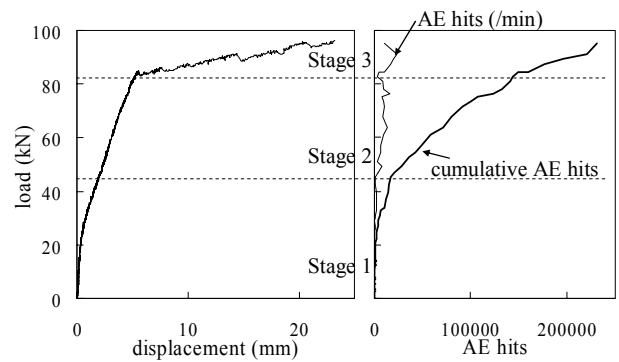

Fig. 12 The relation between load-displacement and AE hits

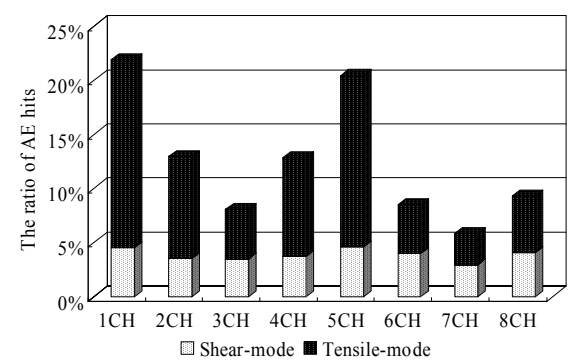

Fig. 14 Results of AE parameter analysis for each sensor

\subsection{AE Parameter Analysis}

Figure 11 shows the loads versus total $\mathrm{AE}$ hits as a function of time. Load versus displacement during the test are shown in Fig. 12. The ultimate load of the RC beam was $96.1 \mathrm{kN}$ and the diagonal-shear failure surely occurred in the shear span of the target as shown in Fig. 13. As load increased, the number of AE hits increased and the hits were obtained acceleratedly near the ultimate load. In Fig. 12, a slope of the load-displacement curve is changed at about $25 \mathrm{kN}$, then AE hits were actively detected.

AE parameter analysis can classify cracks into two types of tensile mode and shear mode (JCMS-III B5706-2003 code) ${ }^{(4)}$. Here, RA value (the rise time/the maximum amplitude) and average frequency (AE ring-down count/the duration time) were applied to the analysis. In total, $69.14 \% \mathrm{AE}$ hits were classified into tensile cracks. For each sensor, however, the ratio of tensile cracks and shear cracks are different as shown in Fig. 14. It is interesting that the ratio of shear cracks seem to be similar in each sensor, regardless of sensor locations. In contrast, the ratios of tensile cracks at channels $1 \mathrm{CH}$ and $5 \mathrm{CH}$ are higher than those of other sensors. As these two sensors were located at the bottom of the beam near the bending span, AE signals due to initiation of bending cracks might be detected selectively.

\subsection{SiGMA Analysis}

The loading process is divided into three stages based on a variation of $\mathrm{AE}$ hits as shown in Fig. 11. At the stage 1, the number of $\mathrm{AE}$ hits was a few until 53 minutes. Bending cracks at the bending (center) span were not visually observed on the surface yet. At the stage 2, a lot of $\mathrm{AE}$ hits were observed, and bending cracks were observed at the center-bottom of the beam until 68 minutes. The number of AE hits (per minute) became the largest at the stage 3 and the diagonal-shear failure occurred in the final moment.

In the SiGMA analysis, AE event definition time (EDT) is set to $120 \mu \mathrm{sec}$. EDT is applied to recognize AE waves occurring within the specified time from the first-hit wave and to classify them as part of the current event. From waveforms of $737 \mathrm{AE}$ events recorded during the four-point bending test, location of $\mathrm{AE}$ sources were determined by reading the arrival times of P-waves. For 292 events out of 737 events, however, the 


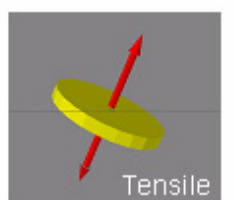

(a) Tensile crack

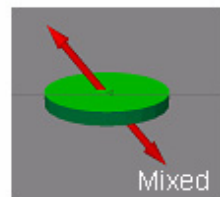

(b) Mixed-mode

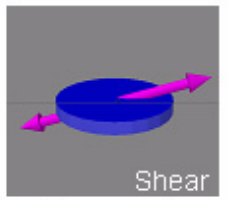

(c) Shear crack
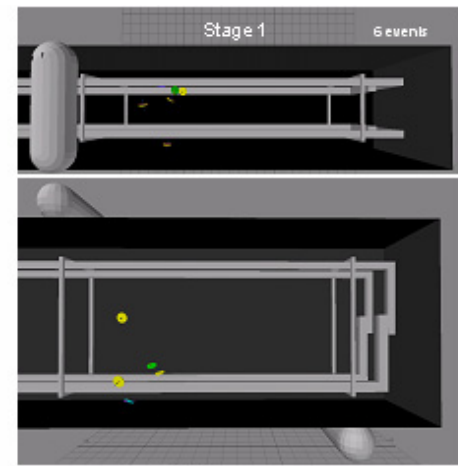

(d) Stage 1
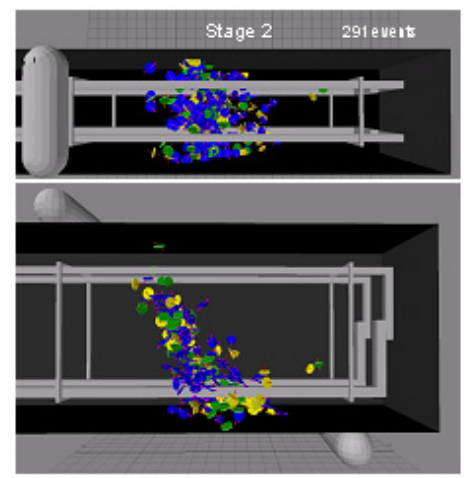

(e) Stage 2

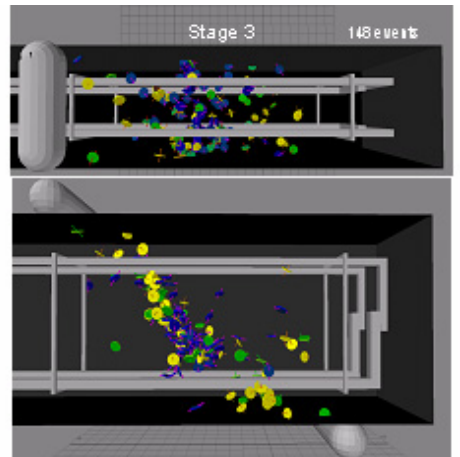

(f) Stage 3

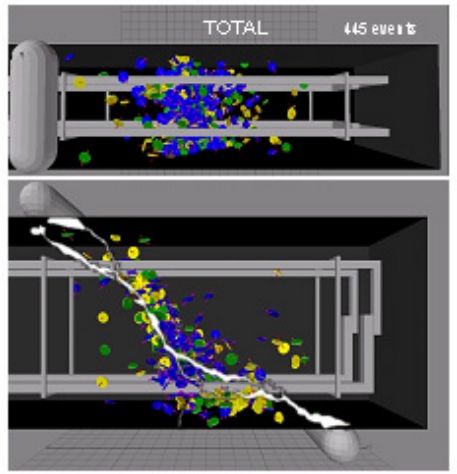

(g) TOTAL

Fig. 15 Results of SiGMA analysis

convergence of solutions could not reach the criterion. Therefore locations of 445 events were determined, and then moment tensor components were determined by reading amplitudes of the first motions. Results of the SiGMA analysis at the three stages are shown in Fig. 15. By employing the Light Wave 3D software (New Tek), a tensile crack is indicated with a yellow disk, direction an opening orientation with an arrow. A mixed-mode crack is denoted with a green disk and a shear crack is shown with a blue disk.

At the stage 1, only six AE events are shown. These events are located mostly near the bending span of the beam. At the stage 2, large number of AE events are observed in the middle of the shear span. It is realized that as the load increases, the area of AE cluster starts to concentrate close to the failure plane in Fig. 15(g). At the stage 2, the diagonal-shear failure was not visually found on the surface of the beam. As seen in the figure, however, large number of micro-cracks are observed in the shear span. At the stage 3 , locations of tensile cracks are mostly observed near the loading point and the support. It suggests the mechanisms that the diagonal-shear failure is initiated at the central area and extends to both ends as tensile cracks are first generated, and then shear cracks follow.

\subsection{Comparison between AE Parameter Analysis and SiGMA Analysis}

Comparison between the results of the AE parameter analysis and those of the SiGMA analysis are given in Fig. 16 and Fig. 17. Most of micro-cracks are classified as tensile cracks in Fig. 16, although the number of shear cracks is dominant in Fig. 17. The difference between the AE parameter analysis and the SiGMA analysis could result from the fact that the AE parameter analysis was carried out for all AE hits, while the SiGMA analysis was applied to only $\mathrm{AE}$ events. In addition, the $\mathrm{AE}$ parameter analysis might include AE events generated in middle of the specimen. This could be a reason why the ratios of the tensile mode are always high in the $\mathrm{AE}$ parameter analysis. As a modified classification, AE sources of which the shear ratios $X$ are greater than $80 \%$ are classified as shear cracks. As referred to as the mixed-mode cracks belonging to tensile cracks, the 


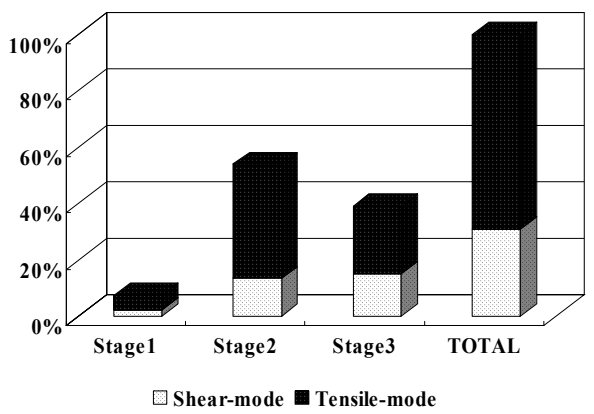

Fig. 16 Results of AE parameter analysis for each stage.

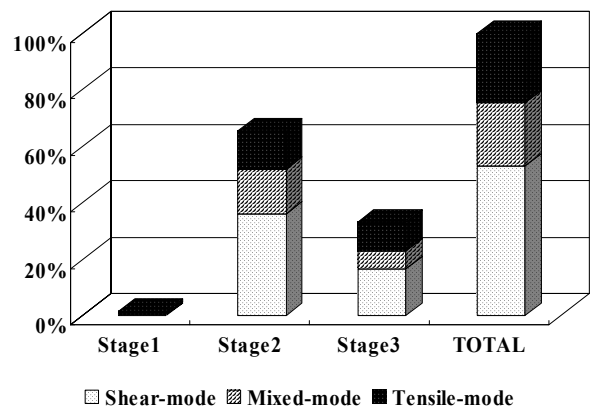

Fig. 17 Results of SiGMA analysis for each stage.

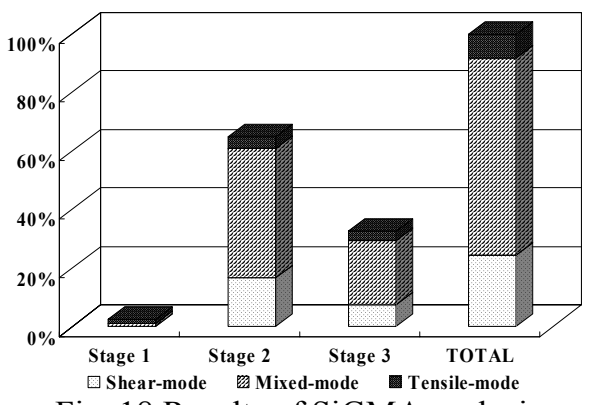

Fig. 18 Results of SiGMA analysis (modified criterion)

ratios of shear cracks in Fig. 18 are in reasonable agreement with those of shear cracks in Fig. 16.

\section{Conclusions}

$\mathrm{AE}$ monitoring was applied to the four-point bending test of an $\mathrm{RC}$ beam and the diagonal-shear failure process was observed. Results obtained are concluded, as follows. 1) In order to determine the optimal array of $\mathrm{AE}$ sensors, theoretical waveforms were calculated and applied to the SiGMA analysis. It is found that 8-channel sensor array could provide better accuracy than 6-channel sensor arrays for classification of crack modes. Therefore, to detect AE events due to the diagonal-shear failure, 8-channnel system was employed for AE monitoring.

2) Three stages of AE generating behaviors were identified. Dominant movements of the diagonal-shear failure were found to be tensile cracks according to the AE parameter analysis. From the SiGMA analysis, however, dominant movements in the shear span were composed of shear cracks. Because the AE parameter analysis was applied to all AE hits, AE sources outside the shear span could be included. This might be a reason why the ratios of the tensile cracks were always high in the AE parameter analysis.

3) Cracking mechanisms determined by the SiGMA analysis were investigated. It suggests the mechanisms that the tensile cracks first are generated, and then the shear cracks follow, creating $\mathrm{AE}$ cluster around the final failure plane. By modifying the criterion, classified results of $\mathrm{AE}$ sources by the $\mathrm{AE}$ parameter analysis are in reasonable agreement with those of the SiGMA analysis.

\section{Acknowledgment}

The authors thank to Dr. Yuichi Tomoda, Kumamoto University, for conducting experiments. It is noted that research achieved in this paper is financially supported by Kumamoto University 21st Century Center of Excellence (COE) Program : Pulsed Power Science and Its Applications. 


\section{References}

(1) Architectural Institute of Japan ed., Report on the Hanshin-Awaji Earthquake Disaster Building Series Volum 1 Structural Damage to Reinforced Concrete Building, ISBN4-8189-2001-0,1997.

(2) M. Ohtsu, The History and Development of Acoustic Emission in Concrete Engineering, Concrete Library of Japan Society of Civil Engineers, No.25(1995), pp.121-134.

(3) M. Ohtsu, Simplified Moment Tensor Analysis and Unified Decomposition of AE Source, Journal of Geophysical Research, Vol.96(1991), No.B4, pp.6211-6221.

(4) Federation of Construction Material Industries, Japan, Monitoring Method for Active Cracks in Concrete by Acoustic Emission, Nondestructive Evaluation of Concrete Properties, 2003, pp.23-28.

(5) M. Ohtsu, K. Ono, A Generalized Theory of Acoustic Emission and Green's Functions in a Half Space, Journal of Acoustic Emission, Vo.3, No.1(1984), pp.124-133.

(6) M. Ohtsu, S. Yuyama, T. Imanaka, Theoretical treatment of acoustic emission sources in microfracturing due to disbonding, The Jounal of the Acoustical Sosiety of America, Vol.82, No.2(1987), pp.506-512.

(7) Knopoff. L, Randall. M.J, The Compensated Linear Vector Dipole : A Possible Mechanism for Deep Earthquake, Journal of Geophysical Research, Vol.75, No.26(1970), pp.4957-4963.

(8) M. Ohtsu, Source mechanism and waveform analysis of acoustic emission in concrete, Journal of Acoustic Emission, Vol.1, No.2(1982), pp.103-112.

(9) M. Ohtsu, K. Ono, AE source location and orientation determination of tensile cracks from surface observation, Non-destructive Testing International, Vol.21, No.3(1988), pp.143-150.

(10) M. Ohtsu, K. Ohno, M. A. Hamstad, Moment Tensors of In-Plane-Waves Analyzed by SiGMA-2D, Journal of Acoustic Emission, Vol.23(2005), pp.47-63. 